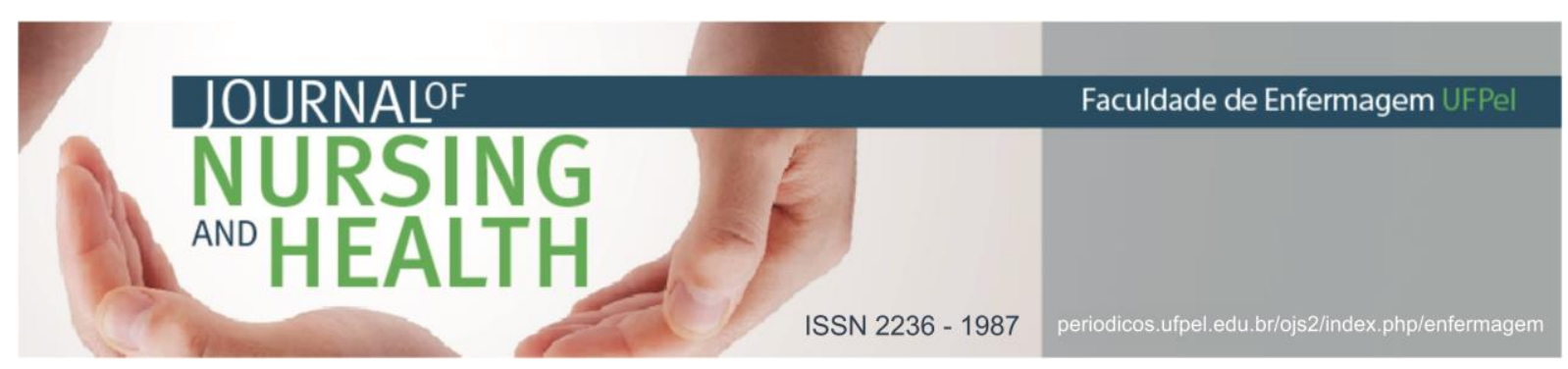

EDITORIAL

\title{
A enfermagem no contexto da pós-graduação brasileira
}

\author{
Nursing in the Brazilian postgraduate context
}

\author{
La enfermería en el contexto del posgrado en brasileño
}

Parada, Cristina Maria Garcia de Limaㅜ; Nichiata, Lucia Izumi²; Kantorski, Luciane Prado ${ }^{3}$

Como citar este editorial: Parada CMGL, Nichiata LI, Kantorski LP. A enfermagem no contexto da pós-graduação brasileira. J. nurs. health. 2019;9(2):e199211

A Enfermagem, enquanto ciência, disciplina e profissão, constitui-se historicamente tendo como objeto de saber e prática o cuidado à saúde do ser humano. Assim, faz-se presente no contexto global, muitas vezes constituindo-se na área profissional mais numerosa em atuação nos sistemas de saúde, desempenhando importante papel em seu desenvolvimento.

Voltada à qualificação dos enfermeiros, a pós-graduação stricto sensu em enfermagem iniciou-se no Brasil em 1972 com o primeiro curso de mestrado criado na Escola Anna Nery. Uma década depois foi criado o primeiro curso de doutorado no país, na Universidade de São Paulo, a partir de um modelo interunidades, esforço conjunto da Escola de Enfermagem e Escola de Enfermagem de Ribeirão Preto. Ao longo de 47 anos, a pós-graduação em enfermagem tem se fortalecido, qualificando a formação profissional e científica de enfermeiros e outros profissionais da área da saúde. ${ }^{1}$

Atualmente, a área de enfermagem possui 54 programas de pós-graduação acadêmicos recomendados pela Coordenação de Aperfeiçoamento de Pessoal de Nível Superior (CAPES), dos quais 16 contam apenas com curso de mestrado, 36 têm cursos de mestrado e doutorado e dois têm exclusivamente curso de doutorado, totalizando 90 cursos. Na modalidade profissional são 24 programas, sendo que 22 deles têm apenas curso de mestrado e dois possuem curso de mestrado e de doutorado, estes últimos aprovados em 2019, totalizando 26 cursos profissionais. ${ }^{2}$

A enfermagem se destaca no contexto da pós-graduação brasileira, por seu protagonismo na formação de mestres profissionais, sendo a Universidade Federal de São Paulo responsável pelo primeiro programa profissional da área, oferecido entre 2002 e 2004. ${ }^{1}$ Assim, esses 17 anos de história e desenvolvimento merecem estar sob foco duas experiências exitosas: 1- o Fórum Nacional de Mestrados Profissionais em

1 Enfermeira. Doutora em Enfermagem. Universidade Estadual Paulista Júlio de Mesquita Filho (UNESP). Coordenação de Aperfeiçoamento de Pessoal de Nível Superior (CAPES). E-mail: cristina.parada@unesp.br http: / / orcid.org/0000-0002-9597-3635

2 Enfermeira. Doutora em Enfermagem. Universidade de São Paulo (USP). Coordenação de Aperfeiçoamento de Pessoal de Nível Superior (CAPES). E-mail: izumi@usp.br http://orcid.org/0000-0001-6515-4404

3 Enfermeira. Doutora em Enfermagem. Universidade Federal de Pelotas (UFPEL). Coordenação de Aperfeiçoamento de Pessoal de Nível Superior (CAPES). E-mail: kantorski@uol.com.br http://orcid.org/00000001-9726-3162 


\section{JOURNALOF

Enfermagem, que em suas nove edições anuais têm promovido discussões relevantes e pertinentes a essa modalidade de formação e contribuído com a divulgação de conhecimento científico-tecnológico produzido no âmbito dos programas e, 2- o Acordo CAPES/COFEN (Edital no 27/2016: Apoio a Programas de Pós-graduação da Área de Enfermagem - Modalidade Mestrado Profissional), ${ }^{3}$ que permitiu 0 financiamento de programas profissionais, traduzindo os esforços da área para avançar na formação stricto sensu voltada à qualificação das práticas e da pesquisa nos serviços de saúde, sendo foco do primeiro Edital, a Sistematização da Assistência de Enfermagem.

Em síntese, em 2019 a área de enfermagem conta com 78 programas de pósgraduação e 116 cursos. A região sudeste possui a maior concentração de cursos, 47 no total $(40,5 \%)$; seguida da região nordeste, com 30 cursos $(25,8 \%)$; região sul, com 25 cursos $(21,6 \%)$; região centro-oeste, com 10 cursos $(8,6 \%)$ e região norte, com quatro cursos $(3,5 \%)$, dos quais dois iniciados em $2019 .{ }^{2}$ Observa-se que apesar do Plano Nacional de Pós-graduação 2011-20204 priorizar a formação em nível de doutorado, inexiste curso de doutorado em enfermagem na região norte do Brasil.

Nesse sentido, a desigualdade na distribuição regional de programas de pósgraduação persiste como desafio que vem sendo enfrentado pela área. Iniciativas de solidariedade, incluindo o desenvolvimento de cursos de doutorado interinstitucional (DINTER), apresenta-se neste cenário como oportunidade de qualificação nas regiões mais descobertas do país. A enfermagem desenvolveu 13 DINTER entre os anos de 2006 e 2017, havendo atualmente outros nove em andamento. ${ }^{2}$

Como estratégia de qualificação voltada ao eixo Sul-Sul, considerando a realidade da América do Sul e o Caribe, a área conta com quatro DINTER internacionais, sendo dois com o Chile, um com o Uruguai e outro com a Colômbia. A enfermagem brasileira mostra sua relevância no cenário internacional também em sua destacada produção científica. No ranking mundial, a partir dos periódicos indexados na base Scopus/SCImago de 2017 (se consideradas todas as áreas do conhecimento) o Brasil é o $14^{\circ}$ país em número de publicações. Quando considerada apenas a Área de Enfermagem, o país assume a nona posição, apenas superada pelos Estados Unidos da América, Reino Unido, Austrália, Canadá, França, Alemanha, China e Espanha. Ainda, analisando o desempenho da Enfermagem a partir da base Scopus/SCImago em 2017, o Brasil apresentou o maior número de publicações (1.565) entre os países da América Latina, número este muito superior ao do México (298), segundo país no ranking. ${ }^{2}$

É basicamente no interior dos programas de pós-graduação que ocorre a produção de pesquisa científica e tecnológica da área. É fato que a totalidade dos bolsistas de produtividade em pesquisa do Conselho Nacional de Pesquisa são docentes de programas de pós-graduação. $O$ fortalecimento da profissão certamente mantém importante relação com a produção de conhecimento científico de excelência e com a consolidação dos programas já existentes.

Como desafios para o desenvolvimento da pós-graduação em enfermagem nos próximos anos estão: a superação das desigualdades regionais na oferta deste tipo 


\section{NURSING \\ AND HEALTH \\ ISSN $2236-1987$}

de formação; a ampliação das pesquisas estratégicas e colaborativas desenvolvidas em busca de respostas às necessidades de saúde dos indivíduos, famílias e populações e do desenvolvimento do Sistema Único de Saúde; a adoção de estratégias de inserção de jovens doutores nos programas, nesse momento de necessidade de renovação do corpo docente; a busca de excelência nacional na formação profissional e na produção de conhecimento; a ampliação da interlocução internacional, contribuindo com o processo de internacionalização da ciência brasileira a partir, entre outras ações, da realização de cooperações institucionais e do desenvolvimento de centros de excelência em ensino e pesquisa, que possam resultar na produção consistente de tecnologia e inovação para o cuidado, gestão e ensino em enfermagem.

A realidade apresentada evidencia importantes desafios da enfermagem frente a sua constituição no interior do Sistema de Pós-Graduação brasileiro e as necessidades de qualificação e expansão no interior dos Sistemas de Saúde e Educação.

\section{Referências}

1 Scochi CGS, Munari DB, Gelbcke FL, Erdmann AL, Gutiérrez MGR, Rodrigues RAP. Pós-graduação stricto sensu em enfermagem no Brasil: avanços e perspectivas. Rev. bras. enferm. [Internet]. 2013[acesso em 2019 jul 22);66(n.esp.):80-9. Disponível em: http://www.scielo.br/pdf/reben/v66nspe/v66nspea11.pdf

2 Coordenação de Aperfeiçoamento de Pessoal de Nível Superior (CAPES). Documento de área 2019. Área 20: enfermagem [Internet]. 2019[acesso em 15 jul 2019]. Disponível

em: https://capes.gov.br/images/Documento_de_área_2019/ENFERMAGEM.pdf

3 Coordenação de Aperfeiçoamento de Pessoal de Nível Superior (CAPES). Conselho Federal de Enfermagem (COFEN). Edital no 27/2016: apoio a programas de pósgraduação da área de enfermagem - modalidade mestrado profissional. Acordo CAPES/COFEN. [Internet]. 2016[acesso em 15 jul 2019]. Disponível em: https://www.capes.gov.br/images/stories/download/editais/05122016-Edital-27Capes-COFEN.pdf

4 Ministério da Educação (BR). Coordenação de Aperfeiçoamento de Pessoal de Nível Superior. Plano Nacional de Pós-Graduação (PNPG): 2011-2020 [Internet]. Brasília: CAPES; 2010[acesso em 15 jul 2019]. Disponível em: https://www.capes.gov.br/images/stories/download/Livros-PNPG-Volume-IMont.pdf 